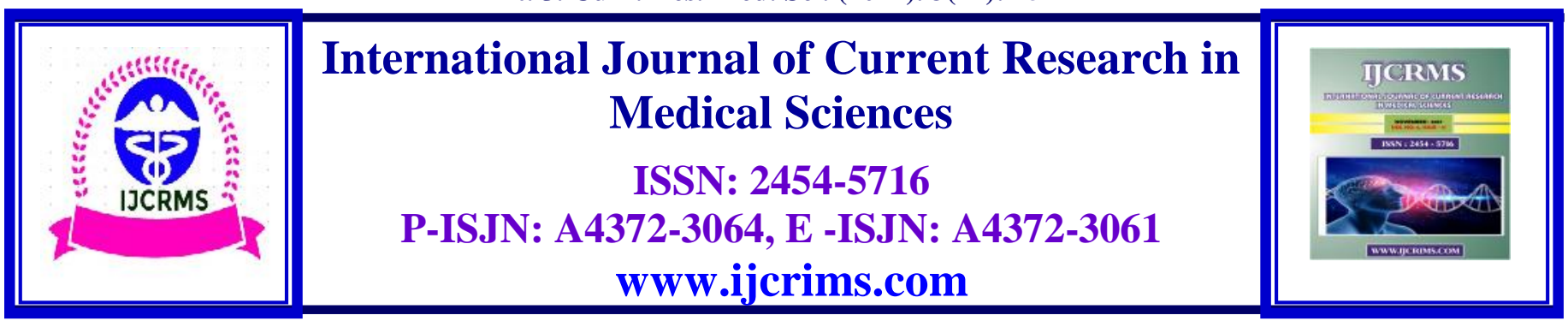

Review Article

Volume 3, Issue 11 -2017

DOI: http://dx.doi.org/10.22192/ijcrms.2017.03.11.006

\title{
A review study of Digital Addiction
}

\begin{abstract}
Ali Mohammadi
MA in Family Counseling, Lecturer Department of Psychology and Counseling, Payam Noor University, International Center of Assaluyeh, Iran
\end{abstract}

Keywords: review study, Digital Addiction

\section{Purpose}

The demands of modern lifestyles have also lead to heavy dependence on various digital technologies for information, inter-personal relationships, entertainment and even economic transactions. There is no doubt that the over dependence on digital technology may result in addiction. Digital addiction is similar to other addictions; those suffering from it exhibit compulsive behaviour and use the virtual fantasy world as a substitution for real-life human connection.However, the dimensions of this issue are so vague and strange. Because although it can despite its impact on society, DA is still considered outside the boundary of the software engineering community. That is, unlike the situation with drugs or alcohol, software engineering has, so far, not been charged with the responsibility for dealing with or mitigating the effects of DA. 
That's why The purpose of the review is to summarize the current scientific knowledge regarding the recently identified and widely circulated terms of Digital Drugs (DD), Digital
Drug addiction (DDA), and Binaural Beats (BB) to offer a scientific based conclusions and recommendations on the handling of DD, DDA, and $\mathrm{BB}$ if existed as a problem.

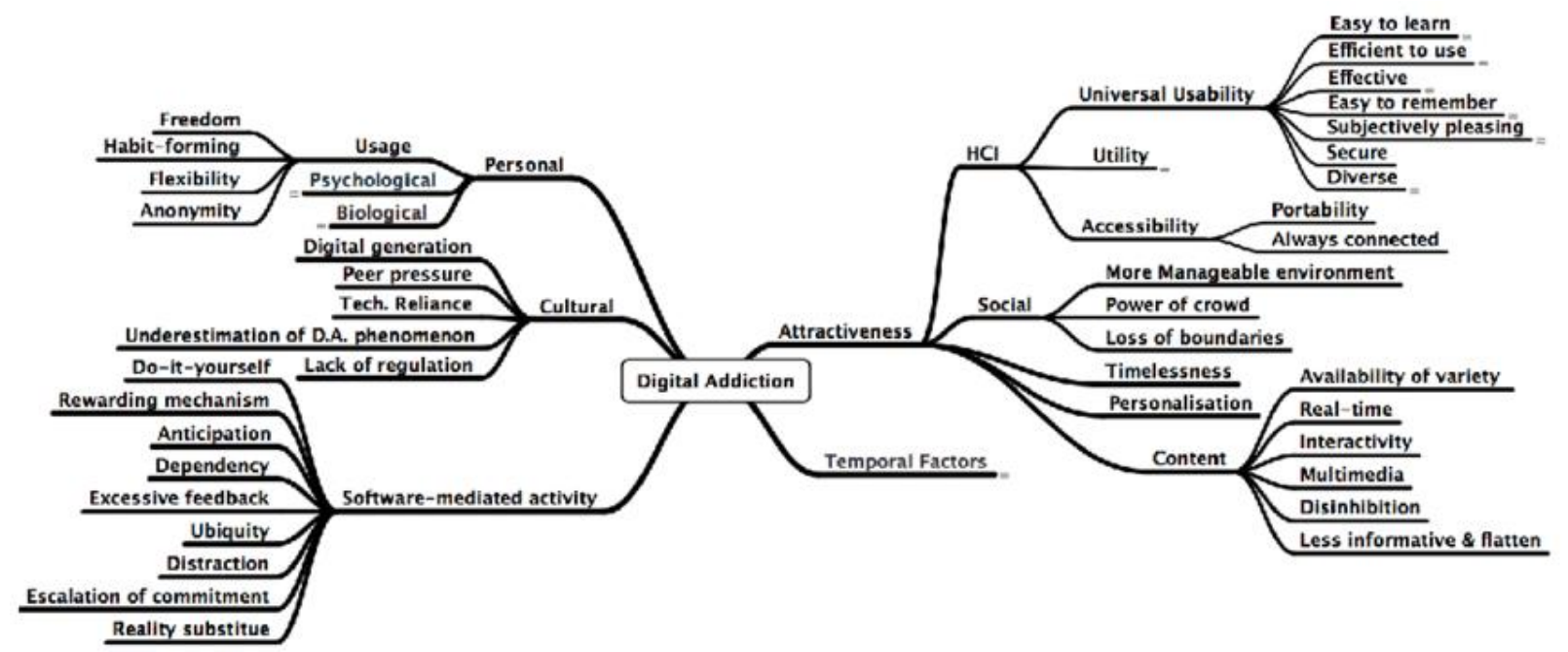

Fig. 1. A mind-map for Digital Addiction

\section{Methods}

We conducted literature searches utilizing nine search engines, namely Medline PubMed, Google, Psych INFO, Science Direct, Springer, ProQuest, Scopus, Elsevier and EBSCO under the terms DDA and or Binaural Beats (BB) Addiction (BBA).

\section{Results}

All search engines did not identify any reported studies or even case reports for DDA or BBA. Many studies have been identified under BB search and they are included in this review. BB may have either inhibitory or stimulatory effect on the brain functions according to the type of BB waves applied to the brain, while others did not demonstrate, reproduce or confirm those findings. Listening to $\mathrm{BB}$ was associated with changes in the mood, where listening to beta $\mathrm{BB}$ frequencies led to enhancing mood, while listening to theta / delta frequencies associated with deterioration of the mood. In addition, listening to alpha BB frequencies was found to help in decreasing anxiety levels. Listening to BB was also associated with enhancing learning abilities, facilitating attention and memory for either healthy subjects or developmentally disabled children or senior personnel. There are contradictory results regarding the EEG and hormonal findings when listening to $\mathrm{BB}$, as not all studies detected the EEG frequencies that may coincide with the listened $\mathrm{BB}$ frequencies or the hormonal changes that moderates the cognitive changes.

\section{Conclusion}

Many studies reported the effect of BB beats on the cognitive functions, EEG changes, and hormones and neurotransmitter changes. Some of these beats have enhancing effects on the brain functions of memory and attention e.g. beta BB, while other have relaxing or inhibiting effects e.g. delta / theta beats. The connection between these effects and EEG and hormonal changes was not established well yet, which needs more research on larger scale and well-designed studies. In spite the evidences of the BB effect on neuropsychological functions, there is no evidences for the addictive nature of the $\mathrm{BB}$ frequencies. We hope that by conducting future research, the challenge of inserting or not incorporating DA will be resolved in the next version of the Diagnostic and Statistical Manual of Mental Disorders (DSM). 
Int. J. Curr. Res. Med. Sci. (2017). 3(11): 25-27

\section{References}

McConnell PA, Froeliger B, Garland EL, Ives JC, Sforzo GA, 2014. Auditory driving of the autonomic nervous system: Listening to thetafrequency binaural beats post-exercise increases parasympathetic activation and sympathetic withdrawal. Front Psychol. 14;5:1248. doi: 10.3389/fpsyg.2014.01248.

Helané Wahbeh, Carlo Calabrese, Heather Zwickey, and Dan Zajdel (2007b). Binaural beat technology in humans: a pilot study to assess neuropsychologic, physiologic, and electroencephalographic effects. The Journal of Alternative and Complementary Medicine. March 2007, 13(2): 199-206.

\begin{tabular}{|c|l|}
\hline \multicolumn{2}{|c|}{ Access this Article in Online } \\
\hline & $\begin{array}{l}\text { Website: } \\
\text { www.ijcrims.com }\end{array}$ \\
\hline Quick Response Code & $\begin{array}{l}\text { Subject: } \\
\text { Psychology and } \\
\text { Counseling }\end{array}$ \\
\hline
\end{tabular}

How to cite this article:

Ali Mohammadi. (2017). A review study of Digital Addiction. Int. J. Curr. Res. Med. Sci. 3(11): 25-27. DOI: http://dx.doi.org/10.22192/ijcrms.2017.03.11.006 